\title{
Pesquisando migrantes forçados e refugiados: reflexões sobre desafios metodológicos no campo de estudos
}

\author{
Julia Bertino Moreira \\ Professora Doutora da Universidade Federal do ABC, Brasil \\ julia.bertino@ufabc.edu.br
}

Resumo $\mathrm{O}$ artigo tem como objetivo primordial discutir os desafios metodológicos envolvidos na realização de pesquisas com migrantes forçados, incluindo refugiados, a partir de uma revisão da literatura desta área de estudos. Para tanto, inicia-se com um debate sobre a construção de categorias em torno de migrantes, como estas são definidas conceitualmente, interpretadas e mobilizadas jurídica e politicamente por atores diversos. Em seguida, faz-se um breve panorama histórico a respeito da constituição do campo de estudos das migrações forçadas e dos refugiados, lançando luz sobre perspectivas atuais em relação ao alargamento das categorias de migrantes consideradas no âmbito das pesquisas. Por fim, adentra-se no debate metodológico propriamente dito, vertendo-se para técnicas e métodos de pesquisa empregados na área e, ao final, explorando a polarização entre as abordagens quantitativa versus qualitativa, assim como limites e possibilidades postas por cada uma delas. Espera-se, com o texto, avançar nas reflexões sobre pesquisas relativas às migrações forçadas nas seguintes dimensões: teórica-conceitual, metodológica e epistemológica.

Palavras-chave: Migrações forçadas, refugiados, categorização, pesquisa, metodologia.

\section{Introdução: a proposta do texto}

A área das migrações forçadas e de estudos sobre refugiados tem sua consolidação relativamente recente, remontando há aproximadamente três décadas. Dentre os desafios que se colocam para o campo na atualidade, emergem questões não apenas teórico-metodológicas, como epistemológicas, e, em especial, sobre quais seriam as fronteiras e intersecções entre tais áreas (inclusive se a segunda estaria contida na primeira). 
Estudiosos procuraram tensionar, ainda, o processo de categorização acerca de migrantes, os quais são divorciados, em primeiro plano, entre voluntários e involuntários. A construção de categorias no âmbito das migrações forçadas se refere à classificação de pessoas em: apátridas - aqueles desprovidos do vínculo jurídico-político com um Estadonação; deslocados internos - aqueles que não conseguem cruzar fronteiras para solicitar proteção a outro Estado; deslocados ambientais - aqueles que migram em função de desastres ou catástrofes naturais que atingem seus países; asilados - categoria aplicável tãosomente ao contexto latino-americano, vinculada a perseguições políticas individuais; e refugiados - sobre a qual verter-se-á o olhar com maior atenção ao longo do texto. Novas categorias vêm sendo aventadas, ao menos teórico-conceitualmente, visando dar conta de fenômenos migratórios que assumem cada vez maior complexidade no cenário internacional contemporâneo.

Da mesma forma, proficuo é o debate a respeito dos métodos e técnicas empregados ao se fazer pesquisas com migrantes forçados e refugiados. A cisão no campo gravita, sobretudo, entre a opção por abordagens quantitativas ou qualitativas, assentada em determinados pressupostos epistemológicos, bem como no escopo das investigações realizadas. As controvérsias vão além, abarcando também as posições e os papéis desempenhados tanto pelo pesquisador quanto por indivíduos ou grupos migrantes pesquisados.

Assim, a proposta do texto é contribuir com reflexões sobre os desafios acima mencionados com os quais frequentemente se deparam pesquisadores no campo, longe da pretensão de oferecer respostas acabadas ou tampouco esgotar tais discussões em curso e extremamente relevantes na área.

\section{Categorização das migrações forçadas}

Como pontuado acima, a área de estudos sobre migrações internacionais convencionalmente se pautou por uma divisão entre as chamadas migrações voluntárias e as migrações forçadas. Se, de um lado, a voluntariedade constituiria o motor fundamental para os processos decisórios que balizam o ato de migrar; de outro, seria a compulsoriedade o fator principal para o deslocamento. $\mathrm{O}$ divisor de águas dos fluxos migratórios parece residir, assim, na contraposição entre o desejo e a violência ${ }^{1}$.

Todavia, tal composição binária comporta questionamentos, tendo em vista que, como bem elucidamVan Hear et al (2009), há aspectos estruturais de caráter compulsório que compelem indivíduos, famílias e outras coletividades a migrar, mesmo quando o fazem por sua própria escolha. É válido citar, nesse caso, situações socioeconômicas graves presentes nos países de origem que colocam em risco a sobrevivência da população local. Ao mesmo tempo, permanece alguma margem de decisão àqueles que são obrigados a deixar seus países de origem e seus lares - a exemplo de refugiados que, mesmo em

1 Reflexão extraída de Malkki (1992, p. 24), para quem "pessoas sempre migraram, seja através do desejo ou através da violência". 
contextos de guerras civis, conseguem por vezes optar, entre escassas possibilidades, para qual país se dirigir. Com isso, pode-se afirmar que há violência em movimentos tidos como voluntários, assim como há desejo(s) permeando os reputados como forçados.

Além disso, nem sempre se revela fácil - ou mesmo possível - distinguir essas categorias de migrantes na prática, o que ficou conhecido na literatura como o nexo migração-refúgio ou a referência a fluxos migratórios mistos (Turton, 2003; Dewind, 2007; Scalettaris, 2007; Chimni, 2009; Chatty, 2016; Chatty; Marfleet, 2013).Turton (2003) entende, assim, que constitui um problema metodológico e ético tentar separar migrantes forçados de migrantes em geral. Como bem lembra o autor, o processo de conceituação se refere à construção de um objeto de conhecimento, constituindo uma representação sobre como interpretamos ou conferimos sentido ao mundo externo. O significado não é algo fixo ou dado, mas resulta de interações entre instituições sociais e culturais. Tal perspectiva crítica transparece crucial ao refletirmos sobre como categorias de migrantes são construídas, reforçadas e interpretadas por diversos atores - internacionais e nacionais, estatais e não estatais - envolvidos na gestão desses movimentos migratórios.

Zetter $(1991,2007)$ despontou como um dos mais árduos críticos acerca dos contornos atribuídos a migrantes a partir de "rótulos", que passam a ser mobilizados por atores em discursos políticos. Tais "rótulos" foram - e ainda são - instrumentalizados sobretudo para descartar determinados migrantes e, simultaneamente, priorizar outros tidos como os reais merecedores de proteção estatal. Dessa forma, os "rótulos" informam respostas políticas aos fluxos migratórios tomadas pelos países receptores e, consequentemente, servem a determinados interesses estatais.

Nesse contexto, situa-se a categoria do "refugiado", construída historicamente como um migrante forçado a fugir de seu país de origem, devido a conflitos internos ou internacionais, instabilidade política, perseguições e outras situações de violência marcadas por violações de direitos humanos. O refugiado, logo, realmente precisaria da proteção de outro Estado, posto que o seu ameaçou ou de fato violou seus direitos ou, ainda, revelou-se incapaz de assegurá-los. Ao mesmo tempo, tal categoria foi edificada de forma estado centrada (Malkki, 1992, 1996; Turton, 2003; Chatty, 2016; Chatty; Marfleet, 2013). Reforçou, com isso, a tríade cidadão - território - Estado, relegando ao refugiado o lugar do des-locado, portanto, do outsider, do outro, do não cidadão, daquele que não possui pertencimento à nação ao transitar entre Estados soberanos (Zetter, 2007; Haddad, 2008; Soguk, 1999; Squire, 2009; Scalettaris, 2007).

Vale lembrar que tal categoria foi constituída no cenário do pós-Segunda Guerra Mundial, a partir de instituições internacionais - dentre as quais merecem destaque a Convenção de 1951 e o Alto Comissariado das Nações Unidas para Refugiados (ACNUR) -, compondo o denominado regime internacional relativo aos refugiados. Tendo como eixo central o "fundado temor de perseguição", a definição elaborada pela Convenção privilegiou não apenas a perseguição, como também cinco motivos que a embasariam: raça, nacionalidade, religião, opiniões políticas e pertencimento a determinado grupo social - portanto, violações a direitos civis e políticos. Tais componentes foram destacados, 
cabe ressaltar, devido a ideias e interesses presentes no pós-guerra, tendo como marco a incipiente Guerra Fria (Loescher, 1996).

Fundado numa perspectiva eurocêntrica, assim como em interesses e controvérsias entre os países que participaram de seu processo de formulação, o regime estruturado pela Convenção lhes impunha parcas obrigações. Isto é, fundamentalmente o dever de não devolver refugiados a países em que suas vidas, segurança ou liberdade pudessem ser ameaçadas - denominado de princípio de non-refoulement (ACNUR, 2015). Como a categoria do "refugiado" servia para reafirmar o próprio Estado-nação enquanto lócus primordial do exercício de poder nas relações internacionais, caberia ao Estado de destino decidir se atribuiria esse status a indivíduos e coletividades que alcançassem seu território em busca de proteção.

Outras categorias de refugiado deitam raízes em experiências e iniciativas particulares regionais, como processos de descolonização e conflitos armados frente a regimes militares. Tanto a Convenção Africana de 1969 quanto a Declaração de Cartagena de 1984 buscaram expandir os contornos da definição dada pela Convenção de 1951. A primeira, aplicável a países da então Organização da Unidade Africana, foi pioneira ao designar "agressão, ocupação externa, dominação estrangeira ou acontecimentos políticos que perturbem gravemente a ordem pública" como elementos centrais para compor a chamada definição ampliada de refugiado (ACNUR, 1969). Já a segunda, aplicável a países latino-americanos, teve como inspiração o precedente africano e incluiu em sua definição a ameaça à vida, segurança ou liberdade, desencadeada pela "violência generalizada, agressão estrangeira, conflitos internos, violação maciça dos direitos humanos ou outras circunstâncias que tenham perturbado gravemente a ordem pública" (ACNUR, 2015, p. 119).

$\mathrm{O}$ debate sobre quais fronteiras delimitam conceitualmente a categoria de refugiado e até que ponto essa pode ser alargada mantém-se atual (Fiddian-Qasmiyeh et al., 2014). Afinal, como bem coloca Zetter (2007), tal categoria se tornou privilegiada frente a outras - em especial à do migrante voluntário, mas também em relação a outros migrantes considerados forçados, como os deslocados ambientais -, de modo que o acesso a ela também se tornou mais restrito. Num cenário internacional, em que populações deslocadas têm aumentado, novas categorias têm sido criadas voltadas a outras formas de proteção ${ }^{2}$, assim como medidas destinadas à contenção dessas pessoas (Chimni, 2009).

De fato, os números de refugiados e outras categorias de migrantes forçados atingiram o maior patamar desde a Segunda Guerra Mundial (quando o regime foi estruturado): 65,6 milhões de pessoas deslocadas, incluindo as categorias de refugiado, deslocado interno, solicitante de refúgio, "pessoas em situações similares a refugio"”, entre outras -

2 Um exemplo especialmente atinente ao contexto brasileiro se traduz na proteção complementar por razões humanitárias, a qual ficou conhecida por "visto humanitário".

3 Categoria (em inglês: people in refugee-like situations) referente a "grupos de pessoas que estão fora de seu país ou território de origem e que enfrentam riscos de proteção similares aos dos refugiados, mas para os quais o status de refugiado, por razões práticas ou outras, não foi determinado" (ACNUR, 2017, p. 71). 
sendo que $84 \%$ desse total se encontra em países do Sul. Os dados disponibilizados pelo ACNUR dão conta de que a maioria dos fluxos se origina em países do Sul e tende a se dirigir a países também do Sul. Tanto que os maiores grupos deslocados em 2016 eram de sírios, palestinos, afegãos, sul-sudaneses, somalis, sudaneses; sendo os maiores países acolhedores: Turquia, Paquistão, Líbano, Irã, Uganda, Etiópia (ACNUR, 2017).

Frente a essa população compelida a se deslocar, países do Norte têm adotado medidas cada vez mais restritivas, colocando em risco o próprio acesso ao refúgio 4 ; simultaneamente, países do $\mathrm{Sul}^{5}$ tampouco se mostram dispostos a ampliar a categoria de refugiado, incluindo nela outras categorias de migrantes forçados. O ACNUR, por sua vez, enquanto agência da ONU designada para os refugiados, procura influenciar os Estados nos processos decisórios em relação à recepção de refugiados. Porém, não raro, tem sua autonomia institucional ${ }^{6}$ questionada face aos interesses de países sobretudo do Norte - maiores doadores da agência e, portanto, responsáveis pelo financiamento de parte significativa de suas operações. Importa mencionar, nesse sentido, que menos de 3\% de seu orçamento provém da ONU e que poucos países ricos se mantiveram historicamente como seus maiores financiadores (Loescher, 2014).

Além dos Estados, do ACNUR, das ONGs e organizações humanitárias que prestam assistência a grupos de migrantes, a Academia também desempenha papel significativo ao refletir sobre o conteúdo atribuído a categorias e as interpretações que assumem ao criticar a instrumentalização feita em torno delas por outros atores e, de modo geral, ao produzir conhecimento sobre tais migrantes.

Deve-se avançar, portanto, não apenas quanto ao debate conceitual sobre a construção das categorias, quais ideias as sustentam, a quais interesses servem, como são mobilizadas em discursos políticos e como são interpretadas por diversos atores, mas também como se produz, dissemina e credita o saber construído a respeito de migrantes - o que nos remete a reflexões teórico-metodológicas e epistemológicas.

\section{Constituição e desenvolvimento do campo de estudos}

A constituição da área de estudos sobre refugiados ${ }^{7}$ remonta ao período de institucionalização do regime internacional relativo aos refugiados, durante a Guerra Fria, assentado na dinâmica da disputa ideológica no eixo Leste-Oeste (Chimni, 2009;

4 Exemplo emblemático consiste no atual acordo entre União Europeia e Turquia com vistas a conter nesse país pessoas que potencialmente se enquadrariam na categoria de refugiado, a fim de que não atinjam o território europeu para solicitar refúgio.Ver: ACNUR, 2016.

5 Conforme explica Menezes (2013), países latino-americanos que adotaram a definição ampliada de refugiado trazida pela Declaração de Cartagena a têm aplicado e interpretado na prática de forma restritiva. O Brasil também pode ser citado como exemplo nesse sentido.

6 O debate sobre a autonomia institucional do ACNUR e sua capacidade decisória para conduzir os rumos de suas atividades é farto - ver, em especial, Loescher, 2014.

7 Em inglês: refugee studies. 
Scalettaris, 2007; Skran; Daughtry, 2007). Como salienta Chimni (2009), o nascimento de uma disciplina não configura um processo a-histórico, ao contrário, encontra-se vinculado à visão de mundo e aos interesses dominantes em determinados contextos sociais, econômicos e políticos.

A partir dos anos 80, uma série de programas e centros de pesquisa, além de publicações específicas sobre refugiados, foram criados em países do Norte. Com relação aos primeiros, destacam-se: o Refugee Studies Programme, instituído em Oxford, Reino Unido, em 1982, que seria rebatizado de Refugee Studies Centre em 2000; e o Refugee Documentation Project, em 1981, em York, Canadá, que viria a se tornar o Centre for Refugee Studies em 1988. O periódico pioneiro foi o Journal for Refugee Studies, publicação de Oxford iniciada em 1988 (Chimni, 2009; Bakewell, 2007; Harrell-Bond; Voutira, 2007; Marfleet, 2007; Black, 2001).

Tal área de estudos foi formada por diferentes perspectivas e contribuições advindas inicialmente da Sociologia, Ciência Política, Geografia, Antropologia, das Relações Internacionais e do Direito e, mais recentemente, da Psicologia e de abordagens críticas, como estudos culturais, pós-coloniais e de gênero (Chatty, 2016; Chatty; Marfleet, 2013; Marfleet, 2007; Voutira; Doná, 2007).

Como afirma Chimni $(1998,2009)$, desde os primórdios da constituição da área de estudos sobre migrações forçadas ${ }^{8}$, a atuação da Academia esteve situada geopoliticamente no Norte, sendo a produção do conhecimento dominada por acadêmicos desse hemisfério. Acrescente-se que a literatura da área foi produzida massivamente por homens, sendo que as mulheres passaram a ter maior espaço tardiamente. Se olharmos sobretudo para as áreas do Direito, da Ciência Política e das Relações Internacionais, predominam pesquisadores homens; na área da Antropologia, de outro lado, pesquisadoras mulheres. Somando-se a isso, vale ressaltar o papel de refugiados acadêmicos, essencialmente de origem europeia, nesse processo de gênese da área (Harrell-Bond;Voutira, 2007).

O conhecimento gerado por tais estudiosos, visto como técnico e especializado, buscou atender particularmente a interesses de países hegemônicos, também servindo à justificação e legitimação de determinadas práticas e políticas adotadas por atores estatais e não estatais. Isso não significa, vale citar, que acadêmicos engajados nessas investigações não tivessem a preocupação de produzir conhecimento com vistas a aprimorar, de alguma maneira, as condições de vida dessas populações (Bakewell, 2007).

Black (2001) reforça que pesquisas acadêmicas no campo foram altamente moldadas por interesses políticos e burocráticos particulares, a partir de demandas feitas não apenas por Estados, como por organizações internacionais e humanitárias (Chatty; Marfleet, 2013). A condução de estudos sobre refugiados e migrantes forçados esteve condicionada, dessa forma, a uma abordagem de "soluções de problemas", tratando, assim, a questão dos

8 Em inglês: forced migration. A tradução, neste artigo, não foi feita de forma literal (no singular), mas no plural, com o fito de destacar que o fenômeno apresenta diversidades, sendo, em si, multifacetado. Supõe-se, com isso, que não há um único fenômeno (homogêneo) da migração forçada, mas vários. 
refugiados como um "problema", que deveria ser atacado a partir de "soluções" - as quais carregam em si, obviamente, alta carga política (Skran; Daughtry, 2007; Black, 2001).

No entender de Chimni (2009), a expansão da área nos anos 80 se deveu à ansiedade dos países do Norte frente a um "problema" em específico: os fluxos migratórios que se avolumavam vindos do Sul. Eis que, em meados dos anos 90, face ao aumento no número de deslocados internos e ao nexo entre migração e refúgio, com os chamados fluxos mistos, passa a haver um declínio relativo nos estudos sobre refugiados, sendo substituídos por estudos sobre migrações forçadas.

Hathaway (2007) questiona a virada de estudos sobre refugiados para estudos sobre migrações forçadas. Incorporar os estudos sobre refugiados no campo mais abrangente dos estudos sobre migrações forçadas poderia significar um fracasso, segundo ele, ante às circunstâncias que definem o refugiado. Além disso, as migrações forçadas enfocam fenômenos, mas não sujeitos - o que poderia colocar em risco a proteção aos refugiados e seus direitos. Adelman e McGrath (2007) criticam Hathaway por enfatizar apenas os refugiados reconhecidos pela Convenção de 1951 - os quais seriam os únicos a receber proteção da comunidade internacional. No mesmo sentido, Cohen (2007) contesta a posição do autor, salientando a tendência de que o número de deslocados internos venha a aumentar (de fato, hoje não apenas ultrapassa o de refugiados, como representa praticamente o dobro deles ${ }^{9}$ ), inclusive por conta dos impactos das mudanças climáticas sobre situações de conflito armado. Dewind (2007) também contra-argumenta Hathaway (2007), amparando-se na dificuldade de distinguir refugiados de outros migrantes forçados igualmente em necessidade de proteção diante da violação a seus direitos humanos. Ilustra, o autor, o caso de pessoas que fogem de privações a seus direitos sociais, econômicos e culturais, não apenas à liberdade e livre expressão de opiniões políticas, tendo seus direitos civis e políticos violados. Bakewell (2008) chama atenção, assim, para o fato de que muitos migrantes permanecem invisíveis aos olhos de pesquisadores.

Diversos autores defendem, portanto, a necessidade de se estender a proteção a outras categorias de migrantes forçados, aos que não são reconhecidos formalmente como refugiados (Dewind, 2007; Cohen, 2007; Betts, 2013; Martin; Weerasinghe; Taylor, 2014; Scallateris, 2007). Alguns, inclusive, ofereceram novas ferramentas conceituais para além da categoria refugiado. Betts (2013, p. 4-5), por exemplo, recentemente elaborou o conceito de "migração de sobrevivência". Refere-se a "pessoas que estão fora de seu país de origem devido à ameaça para acessar uma solução ou remédio doméstico", embora, vale registrar, não seja aplicável aos deslocados internos. O autor destaca, ainda, a importância de se deslocar o foco das causas dos movimentos migratórios para as situações em que se encontram os sujeitos como decorrência desses processos (Betts, 2013). Martin, Weerasinghe e Taylor (2014), por sua vez, desenvolveram o conceito de "migração de crise", em referência aos que migram, bem como aos que ficam retidos - o que incluiria, assim, os deslocados internos - e precisam ser realocados em contextos de

9 Segundo os dados do ACNUR, em 2016, havia 22,5 milhões de refugiados e 40,3 milhões de deslocados internos.Ver:ACNUR, 2017. 
crises humanitárias. Estas são definidas, segundo as autoras, como situações marcadas por ameaça generalizada à vida, segurança, integridade fisica, saúde ou subsistência básica, as quais indivíduos e comunidades residentes não tenham condições de enfrentar.

O debate acerca da definição do objeto de estudo do campo, seus contornos e suas fronteiras é fértil e mantém-se extremamente atual. Para além do que muitos reputam como um déficit de clareza conceitual, o campo apresentaria ainda outras fragilidades, como ausência de uma teoria geral, necessidade de maior rigor analítico e prevalência de estudos empíricos, os quais, não raro, padeceriam de robustez metodológica (Fiddian-Qasmiyeh et al., 2014; Bakewell, 2007; Black, 2001; Jacobsen; Landau, 2003; Chatty; Marfleet, 2013).

\section{Pesquisando migrantes forçados e refugiados ${ }^{10}$}

O campo de estudos sobre refugiados e migrações forçadas, assim como outros, não possui uma metodologia única ou unificada - o que se explicaria por se constituir essencialmente como multidisciplinar, ao abordar uma temática em si interdisciplinar ${ }^{11}$. $\mathrm{O}$ emprego variado de técnicas e métodos de pesquisa - envolvendo desde análise política e jurídica, passando por análise documental com base em arquivos históricos, a estudos econômicos ou etnográficos - deve se pautar pelo desenho da pesquisa e, especialmente, pela questão que a norteia (Skran; Daughtry, 2007; Jacobsen; Landau, 2003; Schmidt, 2007; Colson, 2007; Bloch, 2007).

A seleção de tais técnicas e métodos também depende do alcance que a pesquisa almeja: o uso de entrevistas padronizadas e surveys se justifica para analisar macroprocessos sociais, políticos, econômicos - adotados preponderantemente pela Sociologia e Ciência Política; já entrevistas focalizadas, observação participante e trabalho de campo propiciam uma visão aprofundada em escala micro, privilegiada pela Antropologia (Skran; Daughtry, 2007; Marfleet, 2007; Eastmond, 2007). Dessa forma, coloca-se a preferência por métodos quantitativos ou qualitativos (Schmidt, 2007).

A essa altura, é de se notar que o debate metodológico na área das migrações forçadas se encontra intimamente ligado à discussão mais ampla epistemológica, girando em torno da oposição entre positivismo e pós-positivismo, a qual, por sua vez, insere-se num contexto mais abrangente sobre a produção de conhecimento nas Ciências Sociais ${ }^{12}$. A abordagem denominada de positivista repercutiu nas Ciências Sociais importada das

10 Grande parte da literatura explorada aqui se baseou fundamentalmente em duas edições de dois periódicos de relevo que se dedicaram a discutir metodologia, bem como a própria área, quais sejam: Refugee Survey Quarterly, Oxford, v. 26, n. 3, 2007 e Journal of Refugee Studies, Oxford, v. 20, n. 2, 2007.

11 Concepção elaborada a partir de Voutira e Doná (2007, p. 165-166), para quem "estudos sobre refugiados são multidisciplinar enquanto campo e interdisciplinar em sua abordagem".

12 Sobre este debate, ver, entre outros: DELLA PORTA, Donatella; KEATING, Michael (Ed.). Approaches and Methodologies in the Social Sciences: a pluralist perspective. Cambridge: Cambridge University Press, 2008. 
Ciências Naturais, tidas como a "verdadeira" ciência, buscando imprimir àquelas maior credibilidade e respeitabilidade em seus estudos. Perspectivas mais críticas, no entanto, emergiram a fim de contestar as fundações do positivismo, como o papel da objetividade e da neutralidade em pesquisas realizadas por sujeitos que lidam também com sujeitos, seja indivíduos ou coletividades. ${ }^{13}$

Partindo notadamente do pressuposto positivista, Jacobsen e Landau (2003), em artigo que provocou grande repercussão na área de estudos sobre migrações forçadas, apontavam para a necessidade de maior representatividade, credibilidade, replicabilidade, validade, transparência, capacidade de generalização e comparabilidade nas pesquisas sobre refugiados e migrantes forçados. Alinhadas à tradição voltada para as relações de causalidade, as autoras enfatizavam os princípios de inferência descritiva e causal, assim como o teste de hipóteses a partir de variáveis mensuráveis.

A discussão tecida por Jacobsen e Landau $(2003,2005)$ ecoa muito da argumentação feita por King, Keohane eVerba (1996) em famoso livro que teve alto impacto nas Ciências Sociais, sobretudo na Ciência Política e, posteriormente, nas Relações Internacionais. Não obstante as autoras frisarem inexistir "um único, melhor caminho para assegurar pesquisas centradas em refugiados que seja ética e cientificamente embasada e politicamente orientada" (Jaconsen; Landau, 2003, p. 19), constata-se que elas defendiam epistemológica e metodologicamente os fundamentos, valores e padrões do positivismo, os quais seriam, portanto, aplicáveis a todo tipo de pesquisa. Em outras palavras, seguindo King, Keohane e Verba, a lógica científica da hard Science deveria ser replicada às Ciências Sociais como um todo (Brady; Collier, 2010).

Em contrapartida, diversos acadêmicos dentro da área de migrações forçadas buscaram refutar a dominância do paradigma positivista, sustentando uma concepção reflexivista que vertesse o olhar para as especificidades, diversidades, localidades e contextualizações de tais fenômenos e para como estes são constituídos (Rodgers, 2004; Harrell-Bond;Voutira, 2007; Eastmond, 2007; Lammers, 2007). A preocupação não seria, portanto, com representatividade de amostra e capacidade de generalização. Ao contrário: técnicas qualitativas, como narrativas buscando captar a produção de sentido a partir de experiências singulares subjetivas, permitiriam desconstruir a concepção universal que marca a categoria de refugiado, dando voz a percepções plurais sobre processos migratórios diversificados (Eastmond, 2007; Malkki, 1996). Tais autores criticavam, nesse sentido, a ideia da "experiência do refugiado" como sendo uníssona e homogênea - o que se conecta diretamente à concepção estereotipada da pessoa genérica e abstrata do

13 Adentrando especificamente nas Relações Internacionais, tal debate (denominado terceiro ou quarto debate - de caráter mais epistemológico -, diretamente relacionado ao segundo debate - de teor mais metodológico - nesta disciplina) também ficou conhecido entre racionalistas e reflexivistas, transparecendo uma clara priorização por métodos quantitativos, de um lado, e qualitativos, de outro. Enquanto aqueles teriam como preocupação central a explicação de fenômenos com base em relações de causa e efeito, estes se debruçariam sobre a construção de interpretações a respeito de como fenômenos são constituídos, quais seriam suas características fundantes (Schmidt, 2007; Kurki; Wight, 2010). 
"refugiado". O espaço para multiplicidade de vivências e subjetividades possibilitaria colocar em pauta, não apenas, mas também, questões de gênero - frequentemente silenciadas em tais narrativas e categoria de caráter universalizante (Eastmond, 2007; Malkki, 1996; Colson, 2007; Scalettaris, 2007; Soguk, 1999; Turton, 2003 Godin; Dona, 2016; Doná, 2007; Fiddian-Qasmiyeh et al., 2014). Além disso, para eles, a técnica snowball (bola de neve), vista por Jacobsen e Landau (2003) como produtora de viés por não selecionar aleatoriamente os entrevistados, poderia ser relevante dependendo do objetivo da pesquisa, como compreender a atuação de migrantes em rede (Rodgers, 2004; Schmidt, 2007; Eastmond, 2007; Bloch, 2007; Doná, 2007).

Enormes desafios sobressaem não apenas em termos epistemológicos e das escolhas metodológicas, mas, acima de tudo, da viabilidade de pesquisas a serem conduzidas com migrantes forçados, incluindo refugiados. Como bem pontuam Harrell-Bond e Voutira (2007), essas populações se encontram majoritariamente confinadas em escala mundial, seja em centros de detenção para solicitantes de refúgio em países do Norte, seja em campos de refugiados em países do Sul. O acesso a tais centros, que podem se configurar como prisões fechadas, e campos constitui uma barreira considerável, seja por questões de localização geográfica, logística, segurança; seja pela permissão a ser concedida pelos administradores para que os pesquisadores possam adentrá-los (Harrell-Bond; Voutira, 2007; Bloch, 2007; Jacobsen; Landau, 2003; Rodgers, 2004). No tocante à segurança, por questões de identificação e risco à integridade física, Jacobsen e Landau (2003) alertam que pesquisas também podem colocar em perigo os próprios refugiados e migrantes forçados, especialmente se forem realizadas em zonas de conflito ou áreas de alta vulnerabilidade ${ }^{14}$.

Consequentemente, o acesso em si a estes migrantes representa uma imensa dificuldade, de tal forma que muitos permanecem invisibilizados, mantendo-se inacessíveis a pesquisadores (Harrell-Bond; Voutira, 2007; Bakewell, 2008; Jacobsen; Landau, 2003). Diante de tais obstáculos, nem sempre é possível lidar com amostragem, razão pela qual snowball pode se revelar uma estratégia especialmente útil nesses contextos para se acessar o campo, conjugando-se em paralelo outras técnicas de pesquisa (Bloch, 2007).

Outra questão de relevo no debate posto diz respeito à objetividade, neutralidade e imparcialidade do pesquisador frente ao "objeto" de estudo (Bloch, 2007; Lammers, 2007; Rodgers, 2004; Schmidt, 2007; Bakewell, 2008) - a qual pode ser discutida por vários prismas. Primeiramente, coloca-se o problema do financiamento da pesquisa frente à autonomia institucional e independência intelectual (Bradley, 2007; Scalettaris, 2007; Harrell-Bond; Voutira, 2007; Black, 2001). De fato, desde as origens da disciplina, os estudos estiveram - e ainda estão - condicionados a interesses e prioridades de pesquisa estabelecidos por financiadores, não raro governos, além de organizações internacionais (Bradley, 2007; Black, 2001).Também estiveram, assim, orientados à elaboração de políticas em relação a migrantes forçados acolhidos em países receptores (Landau, 2007; Bakewell, 2008; Black, 2001; Mason, 2007). 
A discussão acerca da utilidade prática em termos políticos das pesquisas realizadas com esses grupos desponta como crucial (Black, 2001; Bakewell, 2008; Jacobsen; Landau, 2003). Jacobsen e Landau (2003, 2005) pontuam, nesse sentido, o "imperativo dual" de se fazer pesquisa com rigor acadêmico e, ao mesmo tempo, com relevância política. A preferência se daria, assim, por pesquisas que apresentassem aplicabilidade prática, contendo números, indicadores, dados estatísticos - portanto variáveis quantificáveis - em relação a pesquisas em nível micro, de maior densidade qualitativa (Schmidt, 2007). Aquelas seriam consideradas capazes de produzir conhecimento científico mais preciso e confiável e, assim, poderiam pautar decisões políticas mais eticamente acertadas (Rodgers, 2004).

Contudo, a busca por relevância política levou muitos pesquisadores a adotar categorias, conceitos e prioridades dadas por políticos e practitioners - restringindo a reflexão conceitual, além de questões levantadas e das opções metodológicas feitas nas pesquisas. Mais do que isso, tais estudos científicos serviram de munição para conferir legitimidade a discursos políticos, reproduzindo os usos e reafirmando a instrumentalização destas categorias. Como nos convida a pensar Bakewell (2008, p. 438): "Se pesquisadores aceitam essas fronteiras do campo e deixam de colocar questões dificeis [...], eles tenderão a confirmar e legitimar pressupostos dados por poderosos atores, como Estados, e assegurar que elas permanecerão subestimadas". Nesse sentido, o autor advoga que pesquisas não orientadas à relevância política podem oferecer críticas mais poderosas e suscitar mudanças mais profundas em relação a processos relativos às migrações forçadas.

Urge aqui, ainda, indagar: até que ponto pesquisas acadêmicas são realmente capazes de influenciar processos decisórios políticos - ou seja, impactar no desenho de políticas? (Black, 2001; Schmidt, 2007). Landau (2007) aponta para o risco de que pesquisas acadêmicas estejam se tornando cada vez mais irrelevantes para políticos e practicioners que atuam diretamente com migrantes forçados. Schmidt (2007), seguindo este entendimento, salienta que avaliações realizadas por acadêmicos sobre políticas institucionais frequentemente acabam sendo engavetadas.

A capacidade de pesquisadores influírem nos processos de tomada de decisões políticas também se conecta à hierarquização marcante na produção do conhecimento feita na área, concentrada, desde os primórdios, geograficamente no Norte (Schmidt, 2007; Chimni, 2009). Tendo em mente que a maior parte do financiamento das pesquisas provém desse hemisfério, pesquisadores do Sul possuiriam capacidade limitada de influência em comparação a pesquisadores do Norte (Bradley, 2007; Landau, 2007).

Segundo Bradley (2007), as parcerias entre pesquisadores do Norte e do Sul se dão, sobretudo, para facilitar o acesso a populações pesquisadas no Sul. De um lado, tais parcerias minam a independência de estudos feitos a partir do Sul ${ }^{15}$ devido à necessidade de se vincular ao Norte para acessar recursos financeiros. Por outro, a autora entende que também abrem oportunidades para troca de novas ideias, possibilitando refinar perspectivas teóricas

15 Segundo Chimni $(2009,1998)$, muito ainda há a ser desenvolvido em termos de produção do conhecimento sobre o Sul - a partir do Sul e para o Sul -, focando em localidades e contextos ricos em especificidades e diversidade acerca das migrações forçadas (ver também Kovacks, 2015). 
sobre um fenômeno que se constitui essencialmente como global(izado). Assim, como já nos advertia Chimni (2009), a produção do conhecimento na área se faz nitidamente a partir de relações de poder, pautadas também pela geopolítica mundial.

Ao olhar para populações majoritariamente provenientes do Sul, sejam localizadas também no Sul ou no Norte, diversos pesquisadores se recusaram a tratá-las como "objetos de estudo", afirmando que são sujeitos de pesquisa (Lammers, 2007; Mackenzie; McDowell; Pittaway, 2007; Eastmond, 2007; Harrell-Bond;Voutira, 2007; Bakewell, 2008). Vale resgatar que a área de estudos sobre migrações forçadas esteve majoritariamente atrelada a um compromisso ético por parte de pesquisadores com a busca por melhorias nas condições de vida de pessoas que enfrentam alto sofrimento humano ${ }^{16}$ (Bakewell, 2008; Turton, 2003).

O engajamento desses pesquisadores enquanto ativistas, militantes, atuando politicamente em prol de migrantes por meio de advocacy, é visto por muitos como inerente a tal compromisso (Schmidt, 2007; Lammers, 2007; Harrell-Bond; Voutira, 2007; Doná, 2007). Outros, porém, entendem ser essa uma das razões para a falta de rigor analítico nos estudos científicos sobre migrações forçadas. Retomando Jacobsen e Landau (2003), o envolvimento direto dos pesquisadores com os pesquisados ensejaria "reatividade" nas pesquisas, de modo que os primeiros poderiam influenciar as respostas destes, comprometendo os resultados atingidos.

Percebe-se que o papel assumido e desempenhado por pesquisadores na realização de estudos com migrantes forçados suscita intensa discussão. Harrell-Bond e Voutira (2007) destacam que, para ser possível a concretização de pesquisas com refugiados, é preciso convencê-los que seus resultados poderão ajudar a melhorar sua situação. $O$ processo de interação entre pesquisadores e pesquisados supõe sensibilidade por parte daqueles, a construção de uma relação de confiança para alcançar a "vontade" (ou "livre consentimento") de participação na pesquisa - posto que refugiados e migrantes forçados podem escolher dela participar ou não ${ }^{17}$ (Lammers, 2007; Bloch, 2007; Mackenzie; McDowell; Pittaway, 2007).

Dado que os pesquisadores também possuem relevante papel de construir sentido às falas dos entrevistados, pode haver preocupação por parte destes em relação a como os dados serão interpretados e aos usos que serão feitos deles (Eastmond, 2007; Lammers, 2007; Bloch, 2007; Mackenzie; McDowell; Pittaway, 2007; Harrell-Bond;Voutira, 2007). De fato, há um elemento central a ser ponderado aqui: os pesquisadores deveriam

16 Outra dificuldade constantemente enfrentada por pesquisadores que estudam migrantes forçados diz respeito à alta carga emocional imbuída nos contextos em que as pesquisas são realizadas (incluindo sensação de impotência diante de situações marcadas por extremo sofrimento humano) (Colson, 2007; Lammers, 2007).

17 A discussão, nesse ponto, traz à tona as dificuldades relativas ao processo de avaliação de projetos por comitês de ética em pesquisa de instituições acadêmicas (majoritariamente dominados por uma perspectiva biomédica), assim como a necessidade de aprovação por agências financiadoras (Harrell-Bond;Voutira, 2007; Mackenzie; McDowell; Pittaway, 2007). 
consultar os entrevistados sobre os significados atribuídos aos seus relatos, o que supõe retornar ao campo, apresentar os resultados de pesquisa e manter diálogo contínuo com os entrevistados. Somente de tal maneira, migrantes e refugiados não serão tratados como meros objetos de pesquisa, como "pesquisados", instrumentalizados, dessa forma, para produzir resultados de pesquisa aos pesquisadores.

Acrescente-se que a confidencialidade dos dados desponta como condição sinequa non para preservar populações mais propícias a vivenciar ou que já passaram por situações de vulnerabilidade, além do cuidado ético em como conduzir a investigação. Landau e Jacobsen $(2003,2005)$ exemplificam, quanto a este ponto, que a técnica de snowball teria o potencial de revelar informações dos membros de uma rede inteira de pessoas inter-relacionadas.

Para além da posição ocupada pelos pesquisadores, é imprescindível problematizar, ainda, o papel atribuído aos migrantes forçados ao longo do processo de pesquisa. Importa pensar sua participação não apenas de forma passiva, como respondentes, entrevistados ou informantes. Castles et al (2002) salientam, com razão, a escassez de pesquisas participativas em que refugiados possam ser envolvidos na fase de desenho das pesquisas, na escolha dos tópicos - até mesmo das questões norteadoras do roteiro das entrevistas - e na realização destas com outros refugiados. Contudo, a atuação de migrantes forçados como pesquisadores, enquanto entrevistadores, por exemplo, igualmente divide acadêmicos da área. Se, para uns, há possibilidade de viés e risco à confidencialidade dos dados coletados (Jacobsen, Landau, 2003); para outros, essa pode ser uma via de acesso ao campo, além de facilitar a aplicação de questionários, evitando o uso de tradutores (Bloch, 2007).

A participação de indivíduos e coletividades migrantes em pesquisas constitui, acima de tudo, uma forma de dar voz a populações constantemente silenciadas - a quem Malkki (1996) apropriadamente nomeou de "emissários sem palavras" (Harrell-Bond;Voutira, 2007; Eastmond, 2007; Lammers, 2007; Mackenzie; McDowell; Pittaway, 2007; Doná, 2007). Em sintonia com o compromisso ético subjacente a essas pesquisas, Rodgers (2004) defende o enorme potencial delas em denunciar abusos encobertos nos deslocamentos em escala global. Castles et al (2002, p. 179) complementam que a participação se faz igualmente "crucial nas avaliações (de políticas) porque permite que os refugiados e migrantes tenham voz a ser ouvida”. Apoiando-se nesse entendimento, Harrell-Bond eVoutira (2007) ressaltam que estudos 'sobre' refugiados vêm caminhando para estudos 'em nome de' refugiados e, conforme pontua Lammers (2007), devem se alçar a estudos 'com' refugiados.

Ainda que se conceba a execução de pesquisas com vistas a propiciar que migrantes possam vocalizar demandas e colocar, a partir de suas próprias perspectivas e percepções, como vivenciam processos migratórios, tal orientação não se encontra isenta de tensionamentos. Partindo das relações de poder que transpassam o processo de pesquisa e definem as posições entre pesquisador e pesquisado, supõe-se que acadêmicos brancos do Norte empoderados permitiriam, assim, que grupos desempoderados oriundos do Sul - ou do mundo 'em eterno’ desenvolvimento - pudessem falar (Rodgers, 2004; Lammers, 2007).

E quem, entre os que foram autorizados, tem espaço de fato para exercer a fala e receber a escuta de outros que estejam em situação de maior poder? Castles et al (2002) destacam 
que determinados grupos podem ser privilegiados frente a outros no âmbito das pesquisas. Solicitantes de refúgio recém-chegados raramente são ouvidos, priorizando-se, por uma série de motivos, a pesquisa com refugiados oficialmente reconhecidos; entrevistas realizadas com líderes comunitários podem não ser representativas da comunidade como um todo, silenciando mulheres ou outros grupos distintos por faixa etária; grupos focais revelam o mesmo problema, ao obstruir vozes menos empoderadas; e até mesmo a utilização de uma única rede social pode impedir a captação da diversidade de outras perspectivas.

Considerando a multiplicidade de sujeitos envolvidos e a complexidade dos processos migratórios em si, o que reverbera nas dificuldades em abordá-los teórico e conceitualmente, bem como em tentar aferi-los metodologicamente, não se pretende, por óbvio, resolver aqui todas as questões levantadas.Propõe-se, antes, guardar um olhar apurado, incessantemente aguçado e reflexivo sobre caminhos para buscar manejá-las, tendo-as presentes no bojo das pesquisas. Afinal, cada opção teórica-conceitual e metodológica acarreta impactos epistemológicos, abrindo certas possibilidades e abrigando consigo determinados limites para a pesquisa. E não se deve perder de vista que, tradicionalmente, esta se faz e é concebida a partir de posições diferenciadas, intrinsecamente perpassadas por relações de poder.

\section{Reflexões finais: entre desafios, limites e possibilidades}

A área sobre migrações forçadas e refugiados é tida como estruturada com escopo interdisciplinar, congregando pesquisadores de variadas formações para se debruçar sobre a compreensão do mesmo objeto de estudo. Como vimos ao longo do texto, a própria área tem se dedicado a (re)pensar conceitualmente os seus contornos, isto é, quais categorias de migrantes conformam seu objeto em si. Em que pese o mainstream das Ciências Sociais, marcado pelo domínio positivista, ter privilegiado o uso de métodos quantitativistas, muitos se opuseram a esse pensamento, destacando a importância da pluralidade de técnicas empregadas na condução de pesquisas realizadas com migrantes.

Posto não haver uma metodologia única, tampouco uma teoria geral a reger a área - o que se reputa salutar, diga-se de passagem -, prepondera a necessidade de se conjugar diferentes instrumentais analíticos e ferramentas metodológicas com vistas a tornar mais sofisticado o saber construído sobre as migrações forçadas. Cabe explorar melhor, por exemplo, o potencial de se casar surveys estatisticamente representativas com entrevistas focalizadas para imprimir maior densidade à análise de experiências subjetivas acerca desses processos migratórios (Castles et al, 2002).

Ancorando-se na constatação de que todas as abordagens metodológicas estão imbricadas de potencialidades, assim como limitações, a intersecção entre diferentes métodos e técnicas compatíveis entre si se faz fortemente relevante, ao buscar contemplar múltiplos aspectos inter-relacionados. Somente operando nessa interface, permite-se 
ampliar e enriquecer o entendimento sobre fenômenos essencialmente complexos e multifacetados (Colson, 2007; Bloch, 2007; Fiddian-Qasmiyeh et al, 2014).

Por fim, cabe ainda a nós, enquanto pesquisadores, refletir profundamente sobre o papel e a posição que ocupamos no percurso da pesquisa, assim sobre aqueles relegados a nossas contrapartes - que merecem ter o reconhecimento como sujeitos. Requer estarmos atentos aos usos que esta possa representar (e possam ser feitos dela), além de como podemos contribuir, mesmo que não intencionalmente, para a reprodução de certos rótulos, parâmetros ou paradigmas que possam rechaçar certos sujeitos ou tratá-los de forma estéril, reafirmando seu lugar de subalternidade. Manter-se firme no compromisso de colaborar, em alguma medida, para conferir maior dignidade às condições de vida destes migrantes implica situar-se no diálogo permanente, estar aberto à escuta sensível e ajudar, de algum modo, a tornar ativas as vozes de pessoas invisibilizadas, historicamente silenciadas e marginalizadas.

\section{Referências}

ACNUR. ACNUR expressa preocupação sobre o acordo entre União Europeia e Turquia. 2016. Disponível em: $<$ http://www.acnur.org/portugues/noticias/noticia/acnur-expressa-preocupacao-sobre-O-acordo-entre-uniaoeuropeia-e-turquia/>. Acesso em: 5 jul. 2016.

Coletânea de Instrumentos de Proteção Nacional e Internacional de Refugiados e Apátridas. 2015. Disponível em: $\quad<$ http://www.acnur.org/t3/fileadmin/scripts/doc.php?file=t3/fileadmin/Documentos/portugues/ Publicacoes/2012/Lei_947_97_e_Coletanea_de_Instrumentos_de_Protecao_Internacional_de_Refugiados_e_ Apatridas>. Acesso em: 5 jul. 2016.

Convention Governing the Specific Aspects of Refugee Problems in Africa. 1969. Disponivel em: <http://www. refworld.org/docid/3ae6b36018.html>. Acesso em: 5 jul. 2016.

Global Trends: forced displacement in 2016. 2017. Disponível em: <http://www.unhcr.org/statistics/ unhcrstats/576408cd7/unhcr-global-trends-2015.html?query=global\%20trends>. Acesso em: 25 jun. 2017.

ADELMAN, Howard; MCGRATH, Susan. To date or to marry: that is the question. Journal of Refugee Studies, Oxford, v. 20, n. 2, p. 376-380, 2007.

BAKEWELL, Oliver. Community services in refugee aid programmes: a critical analysis. New Issues in Refugee Research, Working Paper n. 82, UNHCR, Geneva, 2003. Disponível em: <http://www.unhcr.org/research/ working/3e71f15a4/community-services-refugee-aid-programmes-critical-analysis-oliver-bakewell.html $>$. Acesso em: 5 jul. 2016.

Research beyond the categories: the importance of policy irrelevant research into forced migration. Journal of Refugee Studies, Oxford, v. 21, n. 4, p. 432-453, 2008.

Researching refugees: lessons learned from the past, current challenges and future directions. Refugee Survey Quarterly, Oxford, v. 26, n. 3, p. 6-14, 2007.

BETTS, Alexander. Survival Migration: failed governance and the crisis of displacement. Ithaca: Cornell University Press, 2013.

BLACK, Richard. Fifty years of refugee studies: from theory to policy. International Migration Review, New York, v. 35, n. 1, p. 57-78, 2001.

BLOCH, Alice. Methodological challenges for national and multi-sited comparative survey research. Journal of Refugee Studies, Oxford, v. 20, n. 2, p. 230-247, 2007. 
BRADLEY, Megan. Refugee research agendas: the influence of donors and North-South partnerships. Refugee Survey Quarterly, Oxford, v. 26, n. 3, p. 119-135, 2007.

BRADY, Henry; COLLIER, David (Ed.). Rethinking Social Inquiry: diverse tools, shared standards. Lanham: Rowman \& Littlefield, 2010.

CASTLES, Stephen et al. Integration: mapping the field. London: Home Office Immigration Research and Statistics Service, 2002.

CHATTY, Dawn. Refugee voices: exploring the border zones between States and State bureaucracies. Refuge, Toronto, v. 32, n. 1, p. 3-6, 2016.

CHATTY, Dawn; MARFLEET, Philip. Conceptual problems in forced migration. Refugee Survey Quarterly, Oxford, v. 32, n. 2, p. 1-13, 2013.

CHIMNI, B. S. Reforming the international refugee regime: a dialogic model. Journal of Refugee Studies, Oxford, v. 14, n. 2, p. 151-168, 2001.

. The birth of a 'discipline': from refugee to forced migration studies. Journal of Refugee Studies, Oxford, v. 22, n. 1, p. 11-29, 2009.

.The geopolitics of refugee studies: a view from the South. Journal of Refugee Studies, Oxford, v. 11, n. 4, p. 350-374, 1998.

COHEN, Roberta. Response to Hathaway. Journal of Refugee Studies, Oxford, v. 20, n. 2, p. 370-376, 2007.

COLSON, Elizabeth. Linkages methodologies: no man is an island. Journal of Refugee Studies, Oxford, v. 20, n. 2 , p. 320-333, 2007.

DEWIND, Josh. Response to Hathaway. Journal of Refugee Studies, Oxford, v. 20, n. 2, p. 381-385, 2007.

DONÁ, Giorgia. The microphysics of participation in refugee research. Journal of Refugee Studies, Oxford, v. 20, n. 2, p. 210-229, 2007.

EASTMOND, Marita. Stories as lived experience: narratives in forced migration research. Journal of Refugee Studies, Oxford, v. 20, n. 2, p. 248-264, 2007.

FIDDIAN-QASMIYEH, Elena et al (Ed). Refugee and Forced Migration Studies. Oxford: Oxford University Press, 2014.

GODIN, Marie; DONA, Giorgia. Refugee voices, new social media and politics of representation: young congolese in the diaspora and beyond. Refuge, Toronto, v. 32, n. 1, p. 60-71, 2016.

HADDAD, Emma. The refugee in international society: between sovereigns. Cambridge: Cambridge University Press, 2008.

HARRELL-BOND, Barbara. The experience of refugees as recipients of aid. In: AGER, Alastair (Ed.). Refugees: perspectives on the experience of forced migration. London: Pinter, 1999. p. 136-168.

HARRELL-BOND, Barbara; VOUTIRA, Eftihia. In search of 'invisible' actors: barriers to access in refugee research. Journal of Refugee Studies, Oxford, v. 20, n. 2, p. 281-298, 2007.

HATHAWAY, James. Forced migration studies: could we agry just to 'date'?. Journal of Refugee Studies, Oxford, v. 20, n. 2, p. 350-369, 2007.

. Rejoinder. Journal of Refugee Studies, Oxford, v. 20, n. 2, p. 385-390, 2007.

JACOBSEN, Karen; LANDAU, Loren. Researching refugees: some methodological and ethical considerations in social science and forced migration. Working Paper n. 90, UNHCR Evaluation and Policy Analysis Unit, Geneva, June. 2003. Disponível em: <http://www.unhcr.org/3f13bb967.pdf>. Acesso em: 5 jul. 2016.

KING, Gary; KEOHANE, Robert;VERBA, Sidney. Designing Social Inquiry. Princeton: Princeton University Press, 1996.

KOVACS, Cristina. A critical approach to the production of academic knowledge on refugee integration in the global north. RSC Working Papers, n. 109, Oxford, Refugee Studies Centre, June. 2015. Disponível em: < https:// 
www.rsc.ox.ac.uk/publications/a-critical-approach-to-the-production-of-academic-knowledge-on-refugeeintegration-in-the-global-north>. Acesso em: 5 jul. 2016.

KURKI, Milja; WIGHT, Colin. International Relations and Social Science. In: DUNNE, Tim; KURKI, Milja; SMITH, Steve (Ed.). International Relations Theory: discipline and diversity. Oxford: Oxford University Press, 2010. p. 14-33.

LAMMERS, Ellen. Researching refugees: preoccupations with power and questions of giving. Refugee Survey Quarterly, Oxford, v. 26, n. 3, p. 72-81, 2007.

LANDAU, Loren. Can we talk and nobody is listening? Reflections on IASFM 10, 'Talking across borders: new dialogues in forced migration'. Journal of Refugee Studies, Oxford, v. 20, n. 2, p. 335-348, 2007.

LANDAU, Loren; JACOBSEN, Karen. The value of transparency, replicability and representativeness. Forced Migration Review, Oxford, v. 22, p. 46, 2005.

LOESCHER, Gil. Beyond charity: international cooperation and the global refugee crisis. New York: Oxford University Press, 1996.

UNHCR and forced migration. In: FIDDIAN-QASMIYEH, Elena et al (Ed.). Refugee and Forced Migration Studies. Oxford: Oxford University Press, 2014. p. 215-226.

MACKENZIE, Catriona; MCDOWELL, Christopher; PITTAWAY, Eileen. Beyond 'do no harm': the challenge of constructing ethical relationships in refugee research. Journal of Refugee Studies, Oxford, v. 20, n. 2, p. 299-319, 2007.

MALKKI, Liisa. National geographic: the rooting of peoples and the territorialization of national identity among scholars and refugees. Cultural Anthropology, Houston, v. 7, n. 1, p. 24-44, 1992.

. Speechless emissaries: refugees, humanitarism, and dehistoricization. Cultural Anthropology, Houston, v. 11, n. 3, p. 377-404, 1996.

MARFLEET, Philip. Refugees and history: why we must address the past. Refugee Survey Quarterly, Oxford, v. 26, n. 3, p. 136-148, 2007.

MARTIN, Susan; WEERASINGHE, Sanjula;TAYLOR, Abbie (Ed.). Humanitarian Crises and Migration: causes, consequences and responses. New York: Routledge, 2014.

MASON, Elisa. Keeping up with refugee research. Refugee Survey Quarterly, Oxford, v. 26, n. 3, p. 149-161, 2007.

MENEZES, Fabiano Lourenço de. Fatores causais no reassentamento de refugiados: solidariedade internacional ou interesse estratégico. 2013. Tese (Doutorado em Ciências) - Programa de Pós-Graduação em Integração da América Latina, Universidade de São Paulo, São Paulo, 2013.

OLIVIUS, Elisabeth. (Un)governable subjects: the limits of refugee participation in the promotion of gender equality in humanitarian aid. Journal of Refugee Studies, Oxford, v. 27, n. 1, p. 42-61, 2013.

RODGERS, Graeme. 'Hanging out' with forced migrants: methodological and ethical challenges. Forced Migration Review, Oxford, v. 21, p. 48-49, 2004.

SCALETTARIS, Giulia. Refugee studies and the international refugee regime: a reflecion on a desirable separation. Refugee Survey Quarterly, Oxford, v. 26, n. 3, p. 36-50, 2007.

SCHMIDT, Anna.'I know what you're doing', reflexivity and methods in refugee studies. Refugee Survey Quarterly, Oxford, v. 26, n. 3, p. 82-99, 2007.

SKRAN, Claudena; DAUGHTRY, Carla. The study of refugees before 'refugee studies'. Refugee Survey Quarterly, Oxford, v. 26, n. 3, p. 15-35, 2007.

SOGUK, Nevzat. States and Strangers: Refugees and Displacements of Statecraft. Minneapolis: University of Minnesota Press, 1999.

SQUIRE,Vikki. The Exclusionary Politics of Asylum. New York: Palgrave Macmilliam, 2009. 
TURTON, David. Conceptualising forced migration. RSC Working Paper, n. 12, Refugee Studies Centre, Oxford, Oct. 2003. Disponível em: <https://www.rsc.ox.ac.uk/files/publications/working-paper-series/wp12conceptualising-forced-migration-2003.pdf> . Acesso em: 5 jul. 2016.

VAN HEAR, Nicholas et al. Human development research paper 2009/02 "Managing mobility for human development: the growing silence of mixed migration”. United Nations Development Programme, June. 2009. Disponível em: <http://hdr.undp.org/sites/default/files/hdrp_2009_20.pdf>.Acesso em: 5 jul. 2016.

VOUTIRA, Eftihia; DONÁ, Giorgia. Refugee research methodologies: consolidation and transformation of a field. Journal of Refugee Studies, Oxford, v. 20, n. 2, p. 163-171, 2007.

ZETTER, Roger. Labelling refugees: forming and transforming a bureaucratic identity. Journal of Refugee Studies, Oxford, v. 4, n. 1, p. 39-62, 1991.

More labels, fewer refugees: remaking the refugee label in an era of globalization. Journal of Refugee Studies, Oxford, v. 20, n. 2, p. 172-192, 2007. 


\title{
Inquiry into Forced Migrants and Refugees: reflections on methodological challenges in the field of study
}

\begin{abstract}
The article mainly aims to discuss the methodological challenges involved in conducting research with forced migrants, including refugees. Firstly, it begins debating the construction of categories of migrants, how they are conceptually defined, how they are interpreted, as well as juridically and politically mobilized by different actors. Moreover, it provides a brief historical overview on the constitution of the forced migration and refugee studies area, shedding light on current perspectives in respect to the enlargement of migrants categories considered by researchers on this field. Finally, it focuses on the methodological debate itself, covering the research methods and techniques employed in this field and exploring the quantitative versus qualitative approaches, as well as the limits and possibilities presented by each of them. The purpose of this article is therefore to contribute to conceptual-theoretical, methodological and epistemological assets within the forced migration research field.
\end{abstract}

Key words: forced migration, refugee, categorization, research, methodology.

\section{Investigando migrantes forzados e refugiados: reflexiones sobre desafios metodológicos en el campo de estudios}

\section{Resumen}

El artículo tiene el objetivo primordial de discutir los desafios metodológicos implicados en la realización de investigaciones con migrantes forzados, incluyendo a los refugiados. Para ello, se inicia con un debate sobre la construcción de categorías sobre migrantes, cómo son definidas conceptualmente, interpretadas y movilizadasjurídica y políticamente por diferentes actores. A continuación, se hace un breve panorama histórico sobre la constitución del campo de estudio de las migraciones forzadas y de los refugiados, lanzando una luz sobre las perspectivas actuales con relación a la ampliación de las categorías de migrantes consideradas en el ámbito de las investigaciones. Por último, se profundiza el debate metodológico propiamente dicho, vertiéndose para técnicas y métodos de investigación empleados en el área y, al final, explorando la polarización entre los enfoques cuantitativo versus cualitativo, así como los límites y las posibilidades colocados por cada una de ellas. Se espera que este artículo contribuya para avanzar en las reflexiones sobre investigaciones relativas a las migraciones forzadas en las siguientes dimensiones: teórico-conceptual, metodológica y epistemológica.

Palabras clave: migraciones forzadas, refugiados, categorización, investigación, metodología. 